Universidad de Belgrado

\title{
La crítica de la obra narrativa de Gabriel García Márquez: en las revistas literarias serbias
}

Palabras clave: literatura hispanoamericana, Gabriel García Márquez, realismo mágico, recepción, crítica literaria serbia

Desde que se publicó (1973) la traducción de la novela Cien años de soledad en el idioma serbio no sólo despertó un gran interés la obra de Gabriel García Márquez, sino también la literatura de América Latina, y, sobre todo, la nueva narrativa hispanoamericana, llegaron a ser enormemente populares, tanto entre el gran público como en círculos profesionales. El propósito de este trabajo es presentar, desde una perspectiva cronológica, la relación de la crítica serbia en las revistas literarias (a través de varios ensayos, artículos críticos y estudios) con las obras en prosa (novelas, cuentos) de García Márquez; intentaremos señalar los elementos principales (participantes, evolución de la crítica) de este aspecto interpretativo de la recepción (sin entrar en el análisis de las reseñas) y, al final, procuraremos definir su influencia en la formación del horizonte de expectativas de los lectores en Serbia.

El primero de los críticos serbios que llamó la atención del público sobre la obra narrativa de Gabriel García Márquez fue Vladeta Košutić que, en su ensayo «Ese divino Márquez» (Košutić, 1975), destacó la importancia de la novela Cien años de soledad dentro del marco de la literatura universal. Košutić compara Cien años de soledad de García Márquez con la novela El maestro y Margarita de Mijaíl Bulgákov y llega a la constatación de que las dos obras -por su similar manera de tratar los tema de la soledad y de lo mágico, la fábula, la imaginación estratificada y el procedimiento literario-, representan un nuevo punto de partida en el desarrollo de la prosa contemporánea en el mundo. Sin embargo, lo mágico en Cien años de soledad, a diferencia de lo mágico en El 
maestro y Margarita, no proviene de las fuerzas infernales, sino que se trata de los milagros del destino, hiperbólicos, con una connotación lírica, hechos por su propia cuenta y discretos en su manifestación, que hacen posible la unión natural con la realidad, enriqueciéndola con un simbolismo intencional, pero latente, de pesadumbre, tragedia o pasiones (Košutić, 1975: 4). El análisis de la novela Cien años de soledad empieza con la observación crítica de Mario Vargas Llosa (expuesta en su libro Gabriel García Márquez: bistoria de un deicidio) según la cual el autor se porta en la novela como el Hacedor, o sea, el rival de Dios, y crea su propio mundo imaginario, la gente, el tiempo y las dimensiones que considera convenientes, inspirado en varias fuentes literarias (Faulkner, Hemingway, Defoe, Borges, Las mil y una noches, Camus, Conrad, Virginia Woolf) así como en los recuerdos de la niñez. El tema principal de la soledad, que provoca múltiples milagros, refleja el espíritu humano solitario, callado y vagabundo, y abre el camino al subtema de la soledad de los muertos. Košutić considera que en la obra de García Márquez el tema romántico de los difuntos pobres y solos ( $\tan$ frecuente en Baudelaire, Verlaine, Bécquer, Unamuno y Milosz) es más complejo porque los muertos compadecen a los vivos. Por otro lado, las circunstancias políticas y sociales en América Latina actual, ofrecen otra fuente insaciable a la que García Márquez se refiere muchas veces de forma satírica, de modo que su realismo de repente llega a ser surrealista «sans rien en lui qui pèse ou qui pose» (Košutić, 1975: 4). Se comenta, también, la manera de elaborar el tema de la soledad en El coronel no tiene quien le escriba y se subraya que en este caso se trata de la soledad exclusiva de una profesión y del papel del protagonista que está representado con una mezcla de parodia, tragicomedia y muchos elementos líricos en un proceso de aislamiento y abandono de cualquier clase de relación con la raza humana. Esta novela corta permite al crítico serbio entablar una serie de relaciones: García Márquez se relacionaría con Ionesco o Arrabal, mientras que el coronel se acercaría al Moisés de Alfred de Vigny. Al final, se concluye que El coronel no tiene quien le escriba, con su soledad limitada, no consiguió ni los logros artísticos ni el pronto éxito de Cien años de soledad, la obra maestra que en seguida sedujo al público con soledad orquestada de los Buendía (Košutić, 1975: 5).

El enfoque comparativo caracteriza también el ensayo de Srba Ignjatović «Márquez, entre Borges y García Calderón» (Ignjatović, 1977) que busca las razones del espectacular éxito de la novela Cien años de soledad en el procedimiento como en los temas que se aplican. Con este objetivo, Ignjatović compara los recursos literarios de García Márquez con los de Jorge Luis Borges, Miguel Ángel Asturias y Ventura García Calderón, es decir, con los escritores 
hispanoamericanos que en aquel tiempo ya eran bien conocidos en Serbia a través de sus traducciones y que, con frecuencia, elegían los temas de la misma índole mitológico-legendaria. Igual que Borges, García Márquez tematiza «las rompecabezas intelectuales», pero a diferencia de Borges, que por medio de ellas crea una realidad artística, concentrada e independiente, García Márquez desintegra la realidad así creada por medio de la burla, la paradoja, el humorismo y la ironía, todo ello con el propósito de hacer posible el nuevo establecimiento de su realidad ficticia en una proyección bíblica ( «de 100 años») y dentro del marco de la crónica. Las novelas de Asturias abarcan ciertas situaciones políticas y sociales desde una perspectiva global, mientras que García Márquez representa los acontecimientos en una serie de secuencias cuya vitalidad anula la coherencia de la totalidad (Ignjatović, 1977: 14-15). De los autores mencionados en el título del ensayo, García Márquez está más alejado de García Calderón que, en lugar de reinterpretar los temas míticos, se empeña en crear directamente las situaciones legendarias, sin ninguna clase de transformaciones literarias especulativas. Aunque García Márquez representa, según Srba Ignjatović, una síntesis de temas, procedimientos y recursos literarios tradicionales y modernos (Ignjatović, 1977: 16).

El carácter sintético de la literatura hispanoamericana y la influencia del substrato europeo, sobre todo el español, es subrayado por Krinka Vidaković en el ensayo «Gabriel García Márquez: fantástica y técnica» (Vidaković, 1977). Francia, con sus surrealistas, orientó en gran medida la evolución de la narrativa de Asturias y la acogida de la fantástica intelectual y abstracta de Borges; en cuanto a García Márquez son evidentes las relaciones con Kafka, en la antología Ojos de perro azul y con Faulkner en la novela corta La bojarasca (Vidaković, 1977: 428429). Como Vladeta Košutić, la autora también presta atención especial al tema de la soledad en la obra narrativa de Gabriel García Márquez, pero considera que en sus novelas largas y cortas (Cien años de soledad, El coronel no tiene quien le escriba, La mala hora) y los cuentos (Los funerales de la Mamá Grande) no hay un tratamiento lírico de la soledad, sino más bien una soledad con implicaciones políticas (algo que nunca ocurre en la prosa borgesiana). En este sentido, la visión crítica de Vidaković enriquece la opinión anterior de Košutić, ya que observa una soledad egocéntrica, que en un contexto político representa un deseo enfermizo de gobernar; deseo que se encuentra detrás de todas las farsas políticas cotidianas que producen una imagen distorsionada de la realidad y que, al final, se transforma en una máscara fantástica disimulando la realidad trágica de la vida humana (Vidaković, 1977: 430). La novela Cien años de soledad se refiere a la soledad incorporada en el destino humano y todos los personajes 
son de alguna manera increíbles por tener las virtudes y los defectos o demasiado acentuados o demasiado reprimidos; García Márquez juega con la literatura (como Cervantes) e introduce lo fantástico y lo mítico para romper lo prosaico de la trillada vida cotidiana. Pero, en el caso de la novela El otoño del patriarca el autor se pone detrás de la máscara, precisamente con el fin de desenmascarar por dentro el monstruoso mundo interior del patriarca encerrado en su propia soledad egocéntrica, o, en otras palabras -como dice Krinka Vidaković-, con este tipo del procedimiento narrativo, lleno de metáforas, que empieza con el realismo y termina con el simbolismo, García Márquez vuelve otra vez a la técnica de la novela experimental (Vidaković, 1977: 432-433).

Cuando en los años setenta del siglo pasado el «boom» de la literatura hispanoamericana se convirtió en término conocido en la región del idioma serbio, Branko Andić en el artículo «Abracadabra marquesiana» (Anđić, 1978) hizo referencias críticas al papel que desempeñó García Márquez en la aparición de este fenómeno entre los serbios y señaló la enorme discrepancia en el campo de las traducciones que existía en aquel tiempo en Serbia con respecto a la literatura hispanoamericana: mientras que la demanda de libros de García Márquez no se detenía, las ediciones de otros escritores clásicos de Hispanoamérica (Juan Rulfo, Alejo Carpentier, Carlos Fuentes, Mario Vargas Llosa) pasaron casi desapercibidas y las obras de sus sucesores -autores ya reconocidos (Salvador Elizondo, Guillermo Cabrera Infante, Severo Sarduy, Agustín Yáñez, Daniel Moyano)-, quedaron prácticamente desconocidas. Todo ello ocurrió, según Branko Anđić, porque los lectores serbios creían que al conocer el realismo mágico de García Márquez se estaban acercando a la literatura contemporánea hispanoamericana en general. Sin embargo, algunas malas traducciones pusieran de manifiesto la saturación del mercado en relación con los libros de García Márquez, de esto último el ejemplo más llamativo lo tenemos con el título de la novela corta La bojarasca traducido erróneamente por Obaraska, que para los lectores serbios tiene el significado de «abracadabra» (Anđić, 1978: 3).

Más tarde, Branko Anđić escribe en la crítica «Hora de la antigüedad en el pueblo del Caribe» (Anđić, 1981), sobre la novela Crónica de una muerte anunciada de García Márquez, que estuvo a punto de ser publicada en serbio. Esta vez, Anđić ofrece un análisis de dicha obra (el tema de un asesinato absurdo, la estructura de mosaico, los recursos utilizados - parodia, hipérbola, ironía, ensueños, leyendas, clips de lo cotidiano) para demostrar la habilidad narrativa de García Márquez a la hora de combinar la tradición hispanoamericana (la dicotomía pueblo-ciudad, la figura del macho) con la herencia de la antigüedad (la 
tragedia y su determinación de dar el sentido universal a los acontecimientos locales). La cadena causal de eventos permanece sólo como tal en la estructura de la novela sin garantizar la probabilidad obligatoria; al contrario, el lector se ve obligado a aceptar la concurrencia fatal e inaceptable de circunstancias para reconocer el equilibrio requerido por la justicia cósmica y los valores anteriormente presentados en el libro de cuentos Los funerales de la Mamá Grande (Anđić, 1981:21). La consecuencia final de Crónica de una muerte anunciada, para Branko Anđić, es una sensación de lo vacío y lo absurdo que son las relaciones humanas apócrifas, donde no hay justificación ni cobertura moral alguna.

La interpretación que hace Miroljub Joković de la novela corta El coronel no tiene quien le escriba en «La realidad frustrada» (Joković, 1978), toca puntos referenciales que, según la opinión del autor, tienen una importancia crucial para la formación de la estructura de mosaico que caracteriza dicha obra de García Márquez, cuya idea principal es mostrar la erosión total de los valores humanos, erosión que va desde el núcleo matrimonial hasta el comunitario. Primero, Joković destaca el significado de los sueños que sirven al coronel como último mecanismo de defensa de su identidad contra la presencia socavada y, luego, analiza el papel del gallo como objeto de la frustración tanto en el plano de la comunicación del protagonista con su mujer, como en el plano de la presentación de la comunidad donde el gallo llega a ser una especie de distancia irónica que el coronel mantiene con la gente que le rodea. Al situar la fábula en otoño, García Márquez subraya simbólicamente la visión sombría de la vida en general (Joković, 1978: 5). Teniendo en cuenta que la acción se desarrolla parcialmente de manera lineal y que los personajes a veces carecen de verdadera intensidad psicológica, Miroljub Joković supone que la preferencia del mismo García Márquez por esta corta novela, en comparación con otras obras suyas, se debe a razones privadas del escritor y no a valores puramente artísticos como pudiera pensarse en un primer momento.

Al eco crítico registrado durante los años setenta del siglo pasado en las revistas literarias serbias, se añade el artículo de Milan Vlajčić «La magia de Márquez» (Vlajčić, 1978) en el que se presentan los rasgos principales del realismo mágico de Gabriel García Márquez a partir de dos de sus libros narrativos. Primeramente, Vlajčić nos recuerda que el autor de Cien años de soledad se hizo muy popular en Serbia después de la publicación de esta novela; como ilustración, menciona las tiradas de sus primeras ediciones en serbio y en español, así como la existencia continuada de dicho libro en el mercado literario universal, y comenta la novela (su tema, su procedimiento más propio de la literatura 
oral, los recursos preferidos y el lenguaje) que, realmente, es una síntesis de poesía, humor y parodia. El otro punto de interés de Vlajčić es el libro de cuentos La increíble y triste bistoria de la cándida Eréndira y de su abuela desalma$d a$; el análisis de estos siete relatos, que conforman este recopilatorio, muestra que el estilo de García Márquez sigue siendo el mismo de Cien años de soledad - mágico, virtuoso, llamativo; aunque las acciones ocurren en diferentes lugares y se trasladan generalmente hacia las Islas del Caribe, el autor está todavía inspirado por el mundo mítico de Macondo y utiliza las exageraciones de los cuentacuentos populares (ironía, parodia, farsa, humor) así como los elementos del surrealismo y del género fantástico para expresar el anhelo humano eterno por lo hermoso y lo inalcanzable (Vlajčić, 1978: 627-628).

La cuestión femenina en la literatura hispanoamericana preocupó a la autora Vesna Ristić en un extenso estudio con el título «El amor y la sexualidad de las figuras femeninas en la novela Cien años de soledad» (Ristić, 2007a; Ristić, 2007b), compuesto de dos partes: a) la primera parte (Ristić, 2007a: 126-132) contiene, bajo el prisma general de la soledad como idea principal y el amor como sentimiento dominante, el análisis detallado de la construcción psicológica y la tipología minuciosa de los siguientes personajes femeninos de dicha obra: Úrsula Iguarán (la figura central de Cien años de soledad, la «gran mamá» de la familia Buendía, construida a partir de la mujer más importante en la vida (e ídolo) del escritor - su abuela Tranquilina Iguarán Cortés), Pilar Ternera (altruista, quizá el único personaje de la novela que en su vejez esté liberado de sufrir por soledad), Amaranta y Rebeca Buendía (dos figuras femeninas unidas primero por ser hermanas y amigas y, después, directamente opuestas por asuntos amorosos), Fernanda del Carpio (la figura femenina más negativa, oscura y solitaria de la novela) y Petra Cotes (otra altruista, pero de manera diferente a Pilar, el personaje más humano y noble de Cien años de soledad); b) la segunda parte (Ristić, 2007b: 120-126) está dedicada a la interpretación del procedimiento y los recursos literarios que utilizó García Márquez para llevar a cabo la caracterización de los personajes femeninos en la novela Cien años de soledad y determinar su sexualidad específica. La multiplicación de nombre (tres mujeres se llaman Remedios) sirve para señalar la similitud de su destino (las tres Remedios no llegaron a la madurez por morir o desaparecer muy jóvenes); la facultad de no existir sino en el momento preciso acentúa el papel secundario de la figura femenina (el caso, por ejemplo, de la mujer de Arcadio - Santa Sofía de la Piedad); el olor con efecto afrodisiaco se usa como elemento decisivo de atracción física (Pilar Ternera). La sexualidad es uno de los rasgos básicos de casi todos los personajes de la novela que está llena de 
escenas de relaciones sexuales explícitas. Las figuras femeninas se dividen en aquellas que tienen una sexualidad positiva (Úrsula, Santa Sofía de la Piedad), con una actitud sana hacia el sexo dentro del concepto del amor y de la familia, y otras que tienen una sexualidad negativa (Amaranta, Fernanda del Carpio) que, en realidad, reprimen su sexualidad. Otra clasificación hecha por Ristić distingue a las protagonistas con la sexualidad enfatizada (Pilar Ternera, Amaranta Úrsula) y las mujeres casi asexuales (Remedios Mascote). La sexualidad en la novela Cien años de soledad tiene, también, sus connotaciones negativas: el incesto, como producto del aislamiento y de la soledad (Amaranta, parcialmente - Rebeca, especialmente - Amaranta Úrsula), y la violación provocada por la belleza y la sexualidad fatales de las figuras femeninas (Úrsula, Amaranta Úrsula). En conclusión, se ofrece una visión original de la obra Cien años de soledad como una gran novela femenina; se afirma que las figuras femeninas tienen una ventaja significativa sobre los personajes masculinos porque representan la base estable y el foco de todos los eventos (Ristić, 2007b: 127). La autora del estudio afirma que todas las figuras femeninas se enfrentan con la familia y el hogar o con las relaciones eróticas, de modo que el amor y la sexualidad, es decir, si poseen estas cualidades o no, determinan su destino. Por lo tanto, el mensaje de la novela, sin ninguna duda para Vesna Ristić, es que sólo el amor y la preocupación por otros pueden salvar la civilización moderna del egoísmo y la alienación.

El interés por la iluminación de la narrativa de García Márquez desde el punto de vista genealógico es puesto de manifiesto por Radomir V. Ivanović en diferentes trabajos. En su estudio «Las formas narrativas cortas en prosa de G. G. Márquez» (Ivanović, 2010a) empieza con un resumen de varias definiciones modernas de formas narrativas cortas y largas en general, con el fin de utilizar sus principales postulados en el análisis propio de los cuentos de García Márquez. La actualidad, la autenticidad y la durabilidad del interés de los lectores son las características primordiales de las formas narrativas cortas de Gabriel García Márquez y representan una amalgama de prosa documental y ficción. Sus cuentos, basados muchas veces en anécdotas o en la tradición popular, carecen de episodios y de un proceso de desarrollo de la acción, porque toda la atención del escritor se centra en la tensión dramática y la presión del contexto, lo que los acerca frecuentemente a la prosa poética $y$, a veces, aún más a la prosa rítmica (Ivanović, 2010a: 83-84). El autor del estudio insiste en los parámetros de las formas narrativas cortas de García Márquez (el ambiente fluido, la incompletitud funcional de la acción central y su extrema brevedad) que contribuyeron en gran medida a la afirmación de su prosa en general. El 
cuento más representativo del joven García Márquez, para Ivanović, es Amargura para tres sonámbulos en el que se tratan tres temas -la sombra, la soledad y la evocación-, con una gran economía de recursos literarios; el eje narrativo se encuentra en la interacción de la vida y de la muerte, es decir, en la relación del miedo racional e irracional de la vida, y el perfil de la protagonista, encerrada en su mundo de depresión sin esperanza, muestra los conocimientos psicológicos profundos del autor y su capacidad de penetrar en el subconsciente. El realismo mágico de García Márquez revela también su habilidad de presentar tanto los acontecimientos increíbles como los posibles y verdaderos; se amplía el registro de temas y motivos en su prosa y enriquece la gama de procedimientos literarios aplicados, ejemplo de ello, según la selección de Ivanović, serían los cuentos Alguien desordena estas rosas, La noche de los alcaravanes, Las rosas artificiales y La luz es como el agua (Ivanović, 2010a: 87-88).

En otro estudio «La historia como una confirmación del talento» (Ivanović, 2010b), Radomir Ivanović comprueba que la obra El coronel no tiene quien le escriba es una historia, y no una novela verdadera, debido a la falta evidente de muchos rasgos de la «estructura ausente» propia para la composición novelesca. Ivanović destaca la modernidad, en los niveles estético, poético y creativo, de la confesión íntima titulada El coronel no tiene quien le escriba, modernidad que se basa en la brevedad de su forma épica, en la economía de recursos expresivos y en la evitación de ciertos procedimientos (la literarización y poetización violentas de la historia; la ausencia de una solución que se encuentre en los horizontes esperados por el creador y los lectores; la ausencia de insistencia aparente en el proceso de compasión entre los sujetos épicos y los recipientes. Se analiza la habilidad de García Márquez de contar una historia antigua, pero actual, para cada modelo cultural, de una manera muy simplificada y de construir los personajes en forma de oposiciones binarias utilizando la ironía, el sarcasmo, lo grotesco y el humor (Ivanović, 2010b: 47-48). El crítico serbio revela los niveles de la estructura narrativa (los hechos literales; los hechos menos tangibles caracterizados por giros repentinos; los hechos invisibles que requieren descubrimientos repentinos; las retrospecciones del pasado histórico o familiar) de los que se aprovecha García Márquez para describir el mecanismo de la violencia que hace funcionar el sistema social en Colombia en las primeras décadas del siglo XX. Al final, concluye que el escritor renunció deliberadamente a la utilización de una variedad de estilos, de modo que los significados tácitos o sea los «contenidos ausentes» se pueden comprender como «la recapitulación adicional de la historia» que se lleva a cabo mediante la colaboración del recipiente a partir de su compasión con el protagonista - el coronel (Ivanović, 2010b: 51). 
El análisis de la poética de García Márquez por medio de la interpretación alternativa de sus libros Vivir para contarla y El pez es rojo, es llevado a cabo por Radomir Ivanović en su estudio «El talento lanza el mundo» (Ivanović, 2010c) que consta de tres partes: a) «La correspondencia ideográfica» ofrece un resumen de los últimos hallazgos en la literaturología, especialmente la narratología y la genealogía, y destaca el pensamiento de García Márquez sobre «la hibridación de las culturas», «la hibridación de las lenguas» y «la hibridación de los géneros», que se sublima en la idea de interferencia de los procedimientos creativos y su mutua correspondencia, donde «la voluntad de género» muchas veces supera a «la voluntad de autor» (Ivanović, 2010c: 271); b) «La correspondencia narrativo-escriptiva» revela los principales contornos de la metamorfosis creativa de García Márquez en la que el parámetro crucial es el don de la originalidad o la autenticidad de percibir y elaborar las verdades vistas, ficticias o intuidas (Ivanović, 2010c: 273); c) «La correspondencia entre los géneros literarios» muestra la dominación de la teoría de intervenciones subsiguientes sobre la teoría de la espontaneidad en el proceso creativo de García Márquez, ya que la lectura reversible de sus cuentos y novelas pone de manifiesto que el autor presta atención primero a la fase intencional de nacimiento de una obra (la incubación de inspiración que puede durar varios años), luego a la fase de autocrítica de su propia obra (la selección de una serie de variantes de narración) y, al final, comprueba críticamente los procedimientos creativos aplicados y evalúa rigorosamente los alcances estéticos realizados (Ivanović, 2010c: 281).

Milan Balinda escribió el artículo «Gabo entre las tapas» (Balinda, 2011) con la intención, según la nota introductoria, de presentar las obras más importantes de Gabriel García Márquez en el orden de publicación de sus primeras ediciones en español. Por lo tanto, el artículo consta de los comentarios sobre las (19) obras de García Márquez (novelas, cuentos, reportajes, memorias, obra periodística, discursos) que fueron impresas en el transcurso de más de cincuenta años (1955-2010). Aunque Balinda no tuvo pretensiones científicas de tipo teórico-literario, su artículo ofrece no solamente informaciones interesantes y poco conocidas sobre los libros de García Márquez (cuándo y cómo fueron escritos; las condiciones sociales y privadas - relacionadas con el escritor y su familia- en las cuales fueron creados; las tiradas de las primeras ediciones y su destino, así como el éxito posterior y las traducciones; los premios literarios obtenidos; o las películas basadas en obras de García Márquez), sino que también contiene una visión crítica (el enfoque comparativo de varias obras de García Márquez, los orígenes y génesis de las diferentes versiones de algunos 
libros suyos, los temas, los contenidos, breves análisis de los protagonistas, las fuentes, los rasgos estilísticos, las autoevaluaciones de García Márquez, las opiniones de los críticos literarios) expuesta de manera concisa y muy sugestiva. El estudio de Mila Medigović-Stefanović «El texto es un secreto de parpadeo de la realidad y los sueños» (Medigović-Stefanović, 2011) está dedicado a dos asuntos: a) la reseña crítica (Medigović-Stefanović, 2011: 20-23) de la monografía Los laberintos del realismo maravilloso ${ }^{1}$ de Radomir V. Ivanović en la que el autor intenta reconstruir el sistema narrativo de Gabriel García Márquez a base de análisis narratológico y genealógico, así como de propias experiencias interpretativas y críticas, ocupándose también de varias cuestiones teóricas (la distinción entre el realismo mágico, el realismo maravilloso y el realismo fantástico; los escritores que influyeron decisivamente en la formación literaria de García Márquez); b) la elaboración (Medigović-Stefanović, 2011: 23-27) de algunos temas de la narrativa de García Márquez (Macondo como cronotopo, según Ivanović y la teoría de Bajtín; las influencias positivas y negativas en la selección de los acontecimientos narratológicos; la soledad; el amor y la muerte; Eros; la dictadura).

El estudio comparativo de Damjan Stevkić «La concepción de la historia y la comprensión del pasado en las novelas ;Absalón, Absalón! de William Faulkner y Cien años de soledad de Gabriel García Márquez» (Stevkić, 2013) tiene como el objetivo identificar las diferencias y las similitudes entre los procedimientos literarios de ambos escritores y está compuesto de seis partes: a) «La influencia de William Faulkner en los escritores hispanoamericanos» - la manera faulkneriana de presentar la marginalización regional y el aislamiento económico coincidió con la aspiración de muchos escritores de América Latina en sus intentos de describir la lucha por la independencia del yugo español y la emancipación social y económica (Stevkić, 2013: 73); b) «El grado de influencia de William Faulkner en la obra de G. García Márquez» - gracias a características literarias y culturológicas similares, y a pesar de muchas diferencias (la edad, los estados donde nacieron, las vidas privadas, los compromisos políticos), la influencia de Faulkner en García Márquez es muy fuerte y duradera (Stevkić, 2013: 74); c) «iAbsalón, Absalón! y Cien años de soledad» - la presentación de la realidad fragmentada por medio de varias perspectivas, sin ningún orden cronológico, propia de la narrativa de Faulkner, dejó un rastro profundo en García Márquez al escribir Cien años de soledad (Stevkić, 2013: 75); d) «La concepción de la historia y los sentimientos incestuosos en las obras de W. Faulkner

$1 \quad$ Lavirinti čarobnog realizma (2011). Podgorica 
y G. García Márquez» - ambos autores comprenden el pasado como una parte integral tanto del presente como del futuro en el transcurso espiral del tiempo y que el problema del incesto se puede plantear juntos con el asunto de la mezcla de razas (Stevkić, 2013: 77-9); e) «La atenuación del tiempo en ;Absalón, Absalón!» - los personajes de Faulkner y García Márquez sufren de la soledad, tienen sentimientos incestuosos y rasgos similares que se repiten en todas las generaciones y determinan firmemente sus vidas dentro de un círculo originado en el pasado lejano (Stevkić, 2013: 80); f) «El tratamiento del pasado en Cien años de soledad» - el tiempo narrativo es circular y el pasado pertenece ya al futuro; García Márquez, al igual que Faulkner, crea un tiempo mítico que se opone al tiempo lineal y convencional (Stevkić, 2013: 81-82).

Al final del presente trabajo, se puede concluir que la crítica serbia de la obra narrativa de Gabriel García Márquez que se desarrolló en las revistas literarias en la segunda mitad del siglo XX y a comienzos del siglo XXI (1975-2013), plantea los principales asuntos relacionados con las fuentes, la temática, la estructura, los personajes, los procedimientos y los recursos estilísticos de su prosa. Es evidente que este tipo de crítica literaria varía en su intensidad en el transcurso de las últimas cuatro décadas, pero también es cierto que mantiene un alto nivel de objetividad y razonamiento basado en las teorías y disciplinas literarias modernas como la narratología, la genealogía y la literatura comparada. La mitad de los textos escritos salió en las revistas de Belgrado; por el número (4) de los textos publicados se destacó la revista literaria de la capital serbia Književna reč. En el período investigado, los autores más prolíficos fueron Radomir Ivanović y Branko Anđić. Aunque el enfoque de los críticos serbios se ha centrado mayormente en la novela Cien años de soledad, otras obras narrativas de García Márquez también están presentes en sus análisis, pero todavía ofrecen muchas posibilidades para futuros trabajos que, esperamos, puedan llevarse a cabo de una manera más organizada que hasta ahora.

\section{Bibliografía}

Anđić, B. (1978): «Abracadabra marquesiana». En: Književna reč, 108, 3. Anđić, B. (1981): «Čas antike u karipskom selu». En: Književna reč, 176, 21.

Balinda, M. (2011): «Gabo između korica». En: Savremenik plus, 192/193/194, 42-54.

Ignjatović, S. (1977): «Markes, između Borhesa i Garsije Kalderona». En: Gradina, 2, 14-17. 
Ivanović, R. (2010a): «Kraći pripovedni oblici u prozi G. G. Markesa». En: Trag, 21, 81-92.

Ivanović, R. (2010b): «Povest kao potvrda darovitosti». En: Zlatna greda, 101/102, 46-52.

Ivanović, R. (2010c): «Talenat pokreće svet». En: Godišnjak za srpski jezik i književnost, 10, 267-288.

Joković, M. (1978): «Frustrirana stvarnost». En: Književna reč, 111, 5.

Košutić, V. (1975): «Taj božanstveni Markes». En: Književna reč, 46, 4-5.

Medigović-Stefanović, M. (2011): «Tekst je tajna treperenja stvarnosti i snova». En: Krovovi, 79/80, 20-27.

Ristić, V. (2007a): «Ljubav i seksualnost ženskih figura u romanu Sto godina samoće (I)». En: Sveske, 83, 125-133.

Ristić, V. (2007b): «Ljubav i seksualnost ženskih figura u romanu Sto godina samoće (II) ». En: Sveske, 84, 120-129.

Stevkić, D. (2013): «Koncepcija istorije i shvatanje prošlosti u romanu Vilijema Foknera Avesalome, Avesalome! i Gabrijela Garsije Markesa Sto godina samoće». En: Polja, 484, 73-82.

Vidaković, K. (1977): «Gabrijel Garsija Markes: fantastika i tehnika». En: Savremenik, 5, 427-434.

Vlajčić, M. (1978): «Markesova magija». En: Književnost, LXV/4, 625-628. 


\author{
Vesna Z. Dickov \\ University of Belgrade
}

\title{
Criticism of the narrative works of Gabriel García Márquez in Serbian literary magazines
}

Keywords: Latin American literature, Gabriel García Márquez, magical realism, reception, Serbian literary criticism.

Since the Serbian translation of the novel One Hundred Years of Solitude appeared in 1973, the narrative works of Gabriel García Márquez have continued to interest Serbian critics. After an initial break with readers' expectations, criticism of the magical realism and other aspects of the prose of García Márquez soon (from 1975) began to develop in Serbia, and intensified in the later seventies of the last century as well as at the end of the first decade of the $21^{\text {st }}$ century, when a series of essays, reviews, articles and studies were published on the novels, stories, reportages, essays and memoirs of García Márquez, including his journalistic work. Half of the texts written by Serbian critics for literary journals came out in Belgrade, especially in Književna reč (The Literary Word), the most prolific authors being Radomir Ivanović and Branko Anđić. The judgment of Serbian critics, presented in the literary magazines, which was based frequently on the latest advances in narratology, genealogy and comparative literature, has contributed greatly to the shaping of readers' expectations not only regarding Gabriel García Márquez's prose but also new Latin American narrative in general. 
Vesna Z. Dickov

Univerza v Beogradu

\section{Kritika pripovednega dela Gabriela Garcíe Márqueza v srbskih literarnih revijah}

Ključne besede: hispanoameriška književnost, Gabriel García Márquez, magični realizem, recepcija, srbska literarna kritika

Srbski kritiki vse od izida prevoda romana Sto let samote (1973) z zanimanjem spremljajo delo Gabriela Garcíe Márqueza. Ko so bralci prebrali ta roman, se je začela interpretacija magičnega realizma in drugih vidikov njegove proze zelo hitro razvijati, okrepila pa se je $\mathrm{v}$ sedemdesetih letih preteklega stoletja in v prvem desetletju 21. stoletja, ko je bila objavljena vrsta esejev, kritik, člankov in študij o romanih, zgodbah, reportažah, esejih in spominih Garcíe Márqueza, celo o njegovem novinarskem delu. Polovica besedil, ki so jih napisali srbski kritiki za periodične literarne publikacije, je izšla v Beogradu, predvsem v reviji Književna reč, največ sta jih napisala Radomir Ivanović in Branko Anđić. Mnenje srbske kritike v literarnih revijah, pogosto oprto na zadnje izsledke naratologije, genealogije in primerjalne književnosti, je $\mathrm{v}$ veliki meri prispevalo k oblikovanju obzorja pričakovanj bralcev, ne le glede proznega dela Gabriela Garcíe Márqueza, ampak tudi novega hispanoameriškega pripovedništva nasploh. 